\title{
Chemical Modification of Chitosan in the Absence of Solvent for Diclofenac Sodium Removal: pH and Kinetics Studies
}

\author{
Kerlaine Alexandre Araújo Pereira ${ }^{a}$, Luizangela Reis Osório ${ }^{a}$, Marcos Pereira Silva ${ }^{a}$, \\ Kaline Soares Sousa ${ }^{b}$, Edson Cavalcanti da Silva Filho ${ }^{a *}$ \\ ${ }^{a}$ Interdisciplinary Laboratory of Advanced Materials, Centro de Ciências da Natureza-CCN, \\ Universidade Federal do Piauí - UFPI, CEP 64049-550, Teresina, PI, Brazil \\ ${ }^{b}$ Chemistry Department, Centro de Ciências Exatas e da Natureza - CCEN, \\ Universidade Federal da Paraiba - UFPB, CEP 58051-900, João Pessoa, PB, Brazil
}

Received: July 1, 2013; Revised: January 15, 2014

\begin{abstract}
Chitosan was modified with acetylacetone and ethylenediamine in the absence of solvent. The new biopolymer obtained from the modification was characterized by elemental analysis and NMR ${ }^{13} \mathrm{C}$ and applied in the removal of diclofenac sodium aqueous solution varying the $\mathrm{pH}$ and time. Through elemental analysis was possible to verify a decreasing in $\mathrm{C} / \mathrm{N}$ relation after reaction with acetylacetone and an increasing after modification with ethylenediamine. From NMR analysis was verified the appearance of peaks around 160-210 ppm in both materials due to free carbonyl groups in the first step of the modification, besides the formation of imine bonds. The adsorption tests showed that the highest value occurred at $\mathrm{pH} 4$ and from the results of the kinetic study was found that maximum adsorption occurred within 45 minutes and experimental data adjusted better to linear adjustment, following pseudo second-order model. The results show a material efficient in the removal of emerging pollutants.
\end{abstract}

Keywords: chitosan, modification, sorption, drug, diclofenac sodium

\section{Introduction}

The search for natural materials of low cost and renewable source has greatly increased and among these types of materials biopolymers has excelled. Chitosan is a biopolymer obtained by deacetylation of chitin, which is the second most abundant biopolymer in nature and has been widely studied. One difference that has interested researchers in the study of this biopolymer is the presence of an amino group, which has been quite favorable, since it allows the incorporation of new molecules and has an excellent performance in adsorptive processes, when compared with other biopolymers ${ }^{1-3}$.

The adsorption in biopolymers have been widely investigated, given that the industrial and population progressive growth has exposed the environment to various harmful substances such as pesticides, heavy metals, dyes, petroleum derivatives, pharmaceutical drugs, among others ${ }^{4,5}$. The contamination of aquatic systems by drugs can result from domestic sewage and hospitals where drugs are excreted or discarded ${ }^{5,6}$ in addition to industrial effluents as residues of production ${ }^{7}$.

Thus, concern about drug residues present in the aquatic environment is extremely important, since, they reaching water treatment plants can directly harm the population. This fact makes imperative the control and removal of these pharmaceuticals compounds from the aquatic environment, especially in the case of water for human consumption. Hence, the present study objectives

*e-mail: edsonfilho@ufpi.edu.br the chemical modification of chitosan with acetylacetone and ethylenediamine in the absence of solvent to remove diclofenac sodium from water, checking the influence of $\mathrm{pH}$ and kinetic.

\section{Experimental Part}

\subsection{Material}

Chitosan (Cpure) of medium degree of deacetylation $78 \%$ extracted from crab shell (Primex), acetylacetone (acac) (Vetec), 1,2-ethylenediamine (en) (Vetec), sodium hydroxide (Synth), hydrochloric acid (Sigma), potassium nitrate (Vetec) Diclofenac sodium (DS) (Merck), MilliQ water and acetone (Isopar) were used without prior purification.

\subsection{Modification of chitosan}

The modification of chitosan was carried out with acetylacetone at reflux for 4 hours in the absence of solvent and under constant mechanical stirring ${ }^{8,9}$, where $25 \mathrm{~mL}$ of acetylacetone reacted with $6.0 \mathrm{~g}$ of Cpure. Then the solid was separated and washed with water and dried in an oven at $100{ }^{\circ} \mathrm{C}$. The final material was designated as Cac. Subsequently $5.0 \mathrm{~g}$ of Cac reacted in a similar system with $45 \mathrm{~mL}$ of ethylenediamine under reflux and mechanical stirring for $4 \mathrm{~h}$, being this modified polymer designated as Cacen, and washed with distilled water and dried at $100^{\circ} \mathrm{C}$. 
The proposed reaction scheme of the modification can be seen in Figure 1.

\subsection{Characterizations}

The elemental analysis was performed on a PerkinElmer apparatus, PE 2400 model and the Nuclear Magnetic Resonance in the solid state in the ${ }^{13} \mathrm{C}$ was obtained in an AC400/P Brucker spectrometer with rotation of the magic angle at $75.47 \mathrm{MHz}$, with a relaxation time of $5 \mathrm{~s}$ and contact time of $1 \mathrm{~ms}$.

\subsection{Influence of $\mathrm{pH}$}

For the study of the influence of $\mathrm{pH}$ on the adsorption of diclofenac in the Cacen was used $0.1 \mathrm{~mol} \mathrm{~L}^{-1} \mathrm{HCl}$ and/or $\mathrm{NaOH}$ for adjustment of $\mathrm{pH}$ values of 3 to 10 , using a final concentration of $30 \mathrm{mg} \mathrm{L}^{-1[10,11]}$. Thereafter were removed aliquots of $20.0 \mathrm{~mL}$ from each solution and placed in flasks erlenmeyers containing about $35 \mathrm{mg}$ of Cacen, shaken at $130 \mathrm{rpm}$ for $2 \mathrm{~h}$ at $298 \pm 2 \mathrm{~K}$.

Subsequently, the supernatant was centrifuged at 3500 rpm for 15 minutes and determined the final concentrations of the samples by UV-Vis Spectroscopy using an equipment model of varian CARY 300, at a wavelength of $276 \mathrm{~nm}$, being the amount of drug adsorbed per unit of mass of Cacen in each $\mathrm{pH}\left(\mathrm{q}_{\mathrm{e}}\right.$ in $\left.\mathrm{mg} \mathrm{g}^{-1}\right)$ calculated according to Equation $1^{[12]}$ :

$q_{e}=\frac{\left(C_{i}-C_{f}\right) V}{m}$

where $\mathrm{q}_{\mathrm{e}}\left(\mathrm{mg} \mathrm{g}^{-1}\right)$ is the amount adsorbed per gram of adsorbent; $\mathrm{C}_{\mathrm{i}}$ and $\mathrm{C}_{\mathrm{f}}\left(\mathrm{mg} \mathrm{L}^{-1}\right)$ represent the initial and final concentrations of the samples, respectively; $\mathrm{V}(\mathrm{L})$ is the volume of solution and $\mathrm{m}(\mathrm{g})$ is the mass of the adsorbent.

\subsection{Kinetic study}

To perform the kinetic study of the drug removal, initially was performed an analysis of the influence of time on the study of adsorption of diclofenac, in which was used $20.0 \mathrm{~mL}$ of a $30 \mathrm{mg} \mathrm{L}^{-1}$ drug solution into a series of erlenmeyers flasks containing approximately $35 \mathrm{mg}$ of adsorbent. The samples were placed in a thermostatic bath with orbital agitation using $130 \mathrm{rpm}$ at a temperature of $298 \pm 1 \mathrm{~K}$, at predetermined $\mathrm{pH}$, with times ranging from 0 to 150 minutes. In the range of 15 to 15 minutes, a sample was removed, where the supernatant was separated by centrifugation at $3500 \mathrm{rpm}$ for 15 minutes, and the concentration of the remaining drug was determined in the same way as the $\mathrm{pH}$ study. After the study of the influence of time, the data obtained were adjusted to the models of pseudo first and pseudo second order ${ }^{11}$.

\section{Results and Discussion}

\subsection{Characterization}

In Table 1 are shown the results of the elemental analysis, in which are observed the percentages and quantities in mmol $\mathrm{g}^{-1}$ of carbon and nitrogen of Cpure, Cac and Cacen. Pure chitosan presented $5.49 \mathrm{mmol} \mathrm{g}^{-1}$ of nitrogen and, after reaction with acetylacetone, the amount was reduced to $3.75 \mathrm{mmol} \mathrm{g}^{-1}$, thus causing an increase in $\mathrm{C} / \mathrm{N}$ ratio of 6.13 to 10.44 . This reduction was due to the incorporation of acetylacetone in the structure of chitosan, with incorporation of carbon, hydrogen and oxygen, and a reduction of nitrogen, since in this molecule there is no availability of amino groups ${ }^{13}$.

Chitosan modified with acetylacetone and ethylenediamine showed an increase in nitrogen to 5.66 mmol g-1 and an increase of carbon to $35.00 \mathrm{mmol} \mathrm{g}^{-1}$, causing an increase in $\mathrm{C} / \mathrm{N}$ ratio of 6.13 to 6.18 , compared to Cpure, due to incorporation of the ethylenediamine molecule containing two nitrogen, where one reacted with the carbonyl available of the molecule of acetylacetone, forming a new imine bond and the other staying in the form of $-\mathrm{NH}_{2}$.

The FTIR spectra from chitosan (Cpure) is presented in Figure 2a shows characteristic $\mathrm{C}-\mathrm{H}$ symmetric and asymmetric stretch bands near $2900 \mathrm{~cm}^{-1}$, related to the axial deformation of the $\mathrm{CH}$ bond from $\mathrm{CH}_{2}$ and $\mathrm{CH}_{3}$ groups and an intense and broad band in the region of $3400 \mathrm{~cm}^{-1}$, which is attributed to the stretching vibrations of the $\mathrm{OH}$ groups of the hydroxyls groups of the structure, in addition to physiosorbed water of the biopolymer. Moreover, this also involves the absorption of the NH groups from acetylated units of the biopolymer ${ }^{14}$. Also can be observed the axial deformation of the amide $\mathrm{C}=\mathrm{O}$ at about $1655 \mathrm{~cm}^{-1}$; angular deformation of $\mathrm{NH}$ approximately around $1596 \mathrm{~cm}^{-1}$; axial deformation of amide- $\mathrm{CN}$ around $1421 \mathrm{~cm}^{-1}$; symmetrical
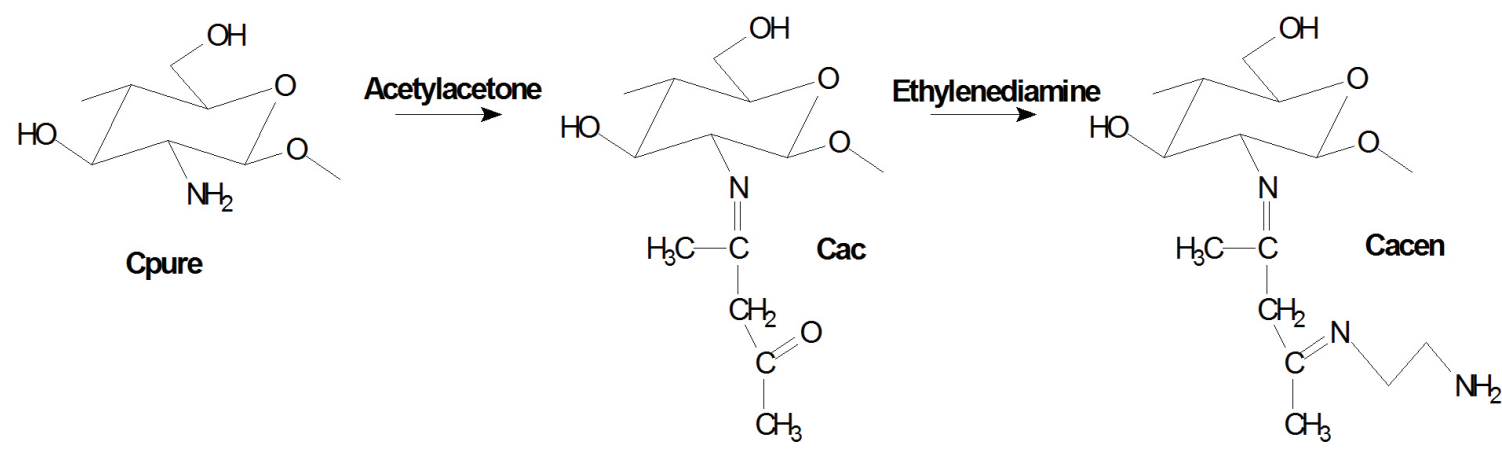

Figure 1. Proposed reaction scheme of the chemical modification of chitosan. 
Table 1. Elemental analysis of Carbon $(\mathrm{C})$, Nitrogen $(\mathrm{N})$, molar amounts of these elements and the respective ratios $(\mathrm{C} / \mathrm{N})$ between these elements to chitosan and its derivative.

\begin{tabular}{cccccc}
\hline Sample & \% $\mathbf{C}$ & $\boldsymbol{\%} \mathbf{N}$ & $\mathbf{C}\left(\mathbf{m m o l ~ \mathbf { g } ^ { - 1 }}\right)$ & $\mathbf{N}\left(\mathbf{m m o l ~ g}^{-\mathbf{1}}\right)$ & $\mathbf{C} / \mathbf{N}$ \\
\hline Cpure & 40.43 & 7.69 & 33.69 & 5.49 & 6.13 \\
Cac & 46.98 & 5.25 & 39.15 & 3.75 & 10.44 \\
Cacen & 42.01 & 7.93 & 35.00 & 5.66 & 6.18 \\
\hline
\end{tabular}

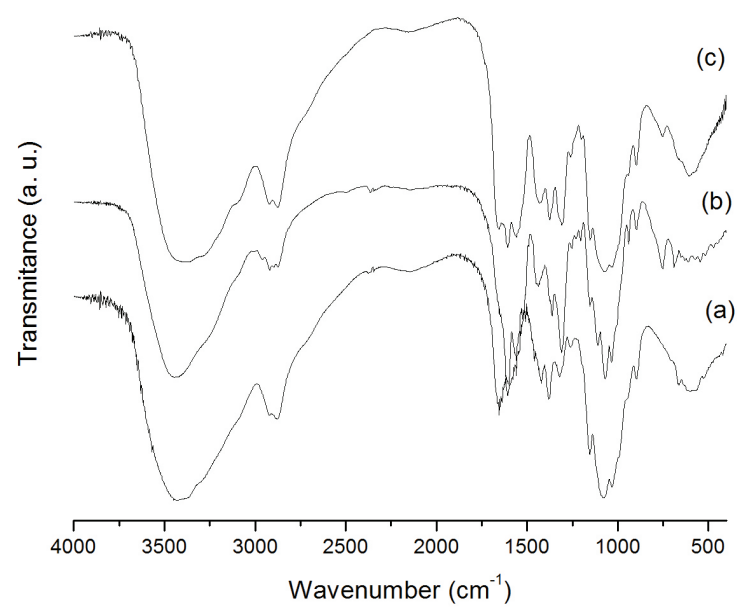

Figure 2. FTIR of the Cpure (a), Cac (b) and Cacen (c).

angular deformation of $\mathrm{CH}_{3}$ at about $1379 \mathrm{~cm}^{-1}$; -CN axial deformation of amino groups between $1323-1379 \mathrm{~cm}^{-1}$ and bands from polysaccharide structure in the region between $897-1153 \mathrm{~cm}^{-1}$. These bands are similar to that presented previously in the literature ${ }^{15,16}$.

A slight change occurs when chitosan is chemically modified with acetylacetone (Cac), shown in Figure 2b, comparing to the characteristic bands in the spectrum of raw chitosan, Q. There is an increasing in intensity and a shift of the band at about $1610 \mathrm{~cm}^{-1}$, related to carbonyl groups and ketone imine bond formation. There is also the appearance of a vibrational band around $1250 \mathrm{~cm}^{-1}$, referring to aliphatic esters groups present in acetylacetone.

In the Cacen spectrum (Figure 2c), there is the appearance of the band at around $1610 \mathrm{~cm}^{-1}$ due to the formation of the imine bond $(\mathrm{C}=\mathrm{N})$ which appears in both $\mathrm{CAC}$ spectrum as the Cacen but with a higher intensity for the latter material due to higher amount of the groups formed after the reaction with ethylenediamine. It is also observed absorptions in the region between 3500-3000 $\mathrm{cm}^{-1}$ assigned to $\mathrm{OH}$ and $\mathrm{NH}$ stretch of amino group $\left(\mathrm{NH}_{2}\right)$ and the free $\mathrm{OH}$ group in the same region of vibration, is related to the presence of secondary amine groups, where there is enlargement and increased intensity of this band .

The presence of the amino group near the carbonyl group of the ketone in Cacen structure causes the appearance of a shoulder and widening of the band at about $1610 \mathrm{~cm}^{-1}$, due to the resonance effect ${ }^{17}$. Is still observed increased intensity of bands related to methyl and methylene groups in the region between $2900-2800 \mathrm{~cm}^{-1}$ due to the groups $\left(\mathrm{CH}_{2}\right)$ ethylenediamine present in the molecule.

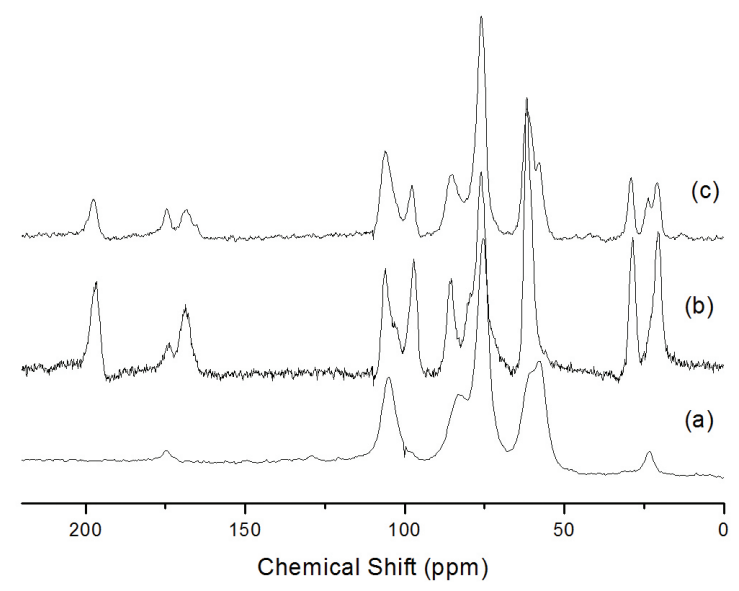

Figure 3. NMR ${ }^{13} \mathrm{C}$ of the Cpure (a), Cac (b) and Cacen (c).

The solid state ${ }^{13} \mathrm{C}$ NMR spectra of Cpure, Cac and Cacen are shown in Figure 3. Cpure presented the characteristic shifts at $105,55,85$ and $60 \mathrm{ppm}$, relative to the carbons $\mathrm{C} 1, \mathrm{C} 2, \mathrm{C} 4, \mathrm{C} 6$, respectively, and at 75 ppm relative to the carbons $\mathrm{C} 3$ and $\mathrm{C} 5$, which are secondary carbons connected to a hydroxyl and to other carbon, respectively, besides the shifts at 22 and $175 \mathrm{ppm}$, associated to the methyl and carbonyl groups, remnants of chitin, as expected, given the degree of deacetylation as being $78 \%{ }^{[9]}$.

The spectrum of Cac (Figure 3b) shows the appearance of a shift at 174 ppm from carbons $\mathrm{C} 7$ and C10, and although may occur displacements in this region due to resonance in the structure of the molecule, this displacement refers to the carbon attached to the nitrogen, which forms the Schiff's base $(\mathrm{C}=\mathrm{N})$. The carbonyl of the structure of acetylacetone appears at $197 \mathrm{ppm}$ and at $20 \mathrm{ppm}$ region are present the shifts referent to the terminals $\mathrm{CH}_{3}$ carbons groups of acetylacetone. Comparing Cacen spectrum (Figure $3 \mathrm{c}$ ) to the spectrum of Cac, can be observed the decrease of the shift at $168 \mathrm{ppm}$, thus confirming the ethylenediamine reaction with the Cac. Changes in a shift around 58 and 23 ppm were also observed, which refers to the carbons present in the molecule of ethylenediamine immobilized ${ }^{18}$.

In Figure 4 are shows the DSC curves from Cpure, $\mathrm{Cac}$ and Cacen. In three spectra, in the temperature range of $60-80{ }^{\circ} \mathrm{C}$, can be ascribed to the loss of water ${ }^{19}$. The second thermal event may be related to the decomposition of amine units correspondent exothermic peak at $301 \mathrm{~K}$ for Cpure. After the first modification with acetylacetone the group is a little more protected and this temperature peak was altered to a maximum of $320^{\circ} \mathrm{C}$. As for the Cacen this temperature decreases to $308{ }^{\circ} \mathrm{C}$ due to the incorporation of ethylenediamine. 


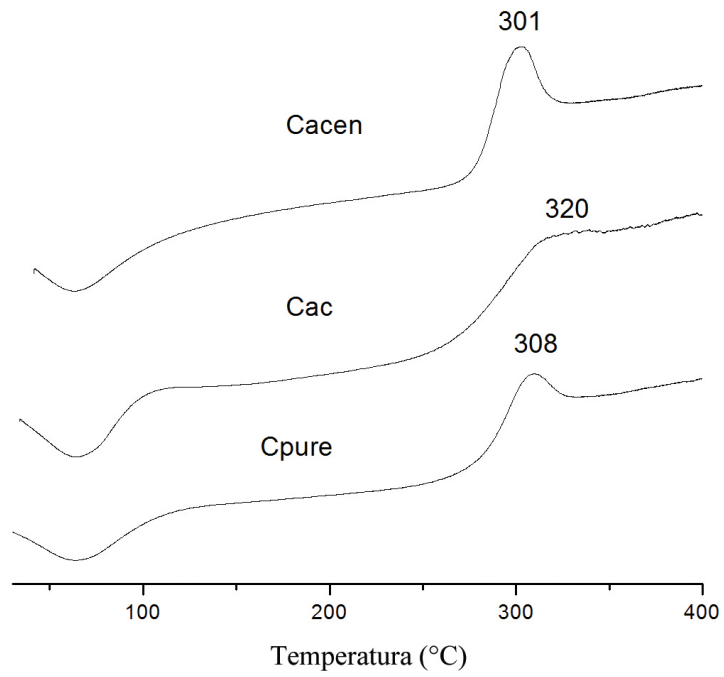

Figure 4. DSC of the Cpure (a), Cac (b) and Cacen (c).

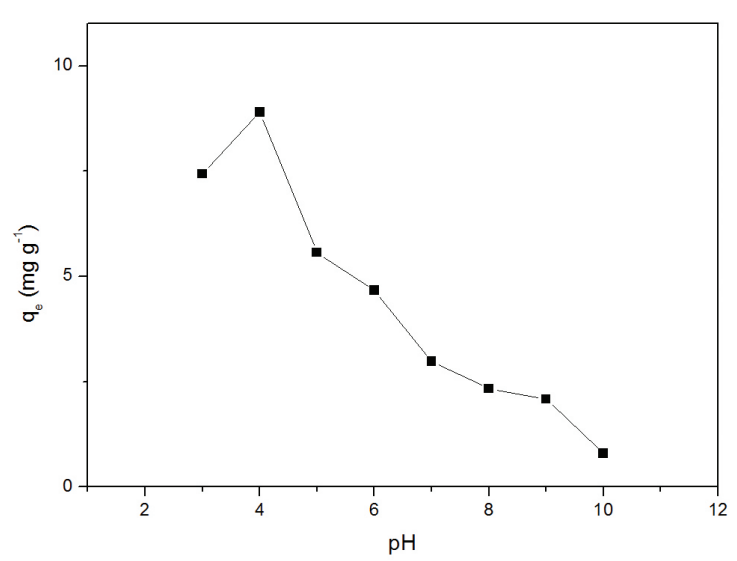

Figure 5. Influence of $\mathrm{pH}$ on the adsorption of DS Cacen.

Table 2. Influence of the time of removal of diclofenac in the Cacen.

\begin{tabular}{cccccccccc}
\hline \multicolumn{10}{c}{ Values } \\
\hline Parameter & \multicolumn{10}{c}{ (mine $(\mathrm{min})$} & 15 & 30 & 45 & 60 & 75 & 90 & 105 & 120 & 240 \\
$\mathrm{q}_{\mathrm{e}}\left(\mathrm{mg} \mathrm{g}^{-1}\right)$ & 9.15 & 8.14 & 9.33 & 9.16 & 8.88 & 8.89 & 8.46 & 9.30 & 9.12 \\
\hline
\end{tabular}

Table 3. Parameters pseudo-first order and pseudo-second order for adsorption of the drug DS by Cacen.

\begin{tabular}{|c|c|c|c|c|c|c|c|}
\hline \multirow{2}{*}{$\frac{\text { Concentration DS }}{\left(\mathrm{mg} \mathrm{L}^{-1}\right)}$} & \multirow{2}{*}{$\frac{q e,_{\exp }}{\left(\mathrm{mg} \mathrm{g}^{-1}\right)}$} & \multicolumn{3}{|c|}{ Pseudo first-order } & \multicolumn{3}{|c|}{ Pseudo second-order } \\
\hline & & $\mathbf{q}_{\mathrm{e}, \text { teo }}\left(\mathbf{m g ~ g}^{-1}\right)$ & $\mathrm{K}_{1}\left(\mathrm{~min}^{-1}\right)$ & $\mathbf{R}^{2}$ & $\mathbf{q}_{\mathrm{e}, \text { teo }}\left(\mathbf{m g ~ g}^{-1}\right)$ & $\mathrm{K}_{2}\left(\mathrm{~g} \mathrm{mg}^{-1} \mathrm{~min}^{-1}\right)$ & $\mathbf{R}^{2}$ \\
\hline 30 & 9.33 & 0.59 & 0.0051 & 0.0784 & 9.13 & 0.0383 & 0.9938 \\
\hline
\end{tabular}

\subsection{Adsorption test}

\subsubsection{Influence of $\mathrm{pH}$}

The adsorption most often varies with the $\mathrm{pH}$, depending on the materials used, which can influence the adsorbent/ adsorbate interaction. In the case of diclofenac, the interaction with activated charcoal occurred due to a nonelectrostatic interaction involving the hydrogen bond ${ }^{20}$. This hydrogen bond occurs mainly at a $\mathrm{pH}$ below 7.6, a value at which the carbonaceous surface has a positive global charge; however, it becomes less favorable on negative carbonaceous surface at $\mathrm{pH}$ above 7.6.

Figure 5 presents the data of the influence of $\mathrm{pH}$ in the interaction between diclofenac sodium and Cacen. The system DS-Cacen showed a greater amount of drug adsorbed in the range of $\mathrm{pH}$ equal to 4 , decreasing as the $\mathrm{pH}$ increases. Antunes et al. ${ }^{10}$ have demonstrated the adsorption of DS using grape marc 'isabel' brand and chose to work with the drug solution at its natural pH in Milli-Q water (about 5.0). Thus, as the modified chitosan is protonated in such $\mathrm{pH}$, the electrostatic interactions favored the process of removing the drug from aqueous solution.

According Kranjisnik et al. ${ }^{20}$, diclofenac is a hydrophobic organic molecule, poorly soluble in water, a weak organic acid and at $\mathrm{pH} 7.4$ (phosphate buffer) exists in ionized anionic form (over 90\%). They used a natural zeolite modified for adsorption of DS and concluded that DS was adsorbed in the hydrophobic phase by the creation of groups of the surfactant on the surface of zeolite.

\subsection{Kinetic study}

Table 2 presents the data concerning to the influence of time between Cacen and the drug studied.

From the data presented it can be observed that in 45 minutes occurs the maximum adsorption with little variation in the remaining time, thus showing that adsorption occurs at excellent time when compared with other materials, such as the one studied by Antunes et al. ${ }^{10}$, in which the equilibrium time was 80 minutes for the same concentration studied in this work. In Table 3 are the parameters obtained by kinetic models of pseudo first and second order.

After analyzing the results it was found that the experimental data has better adjusted to the pseudo secondorder model, due to its linearity and by the value of $q_{e, \text { teo }}$ appears very close to the value of $q_{e, \text { exp }}$. The values of $q_{e}$ were much higher than those reported by Bui and Choi ${ }^{21}$, who evaluated the adsorption of DS by mesoporous silica SBA-15. They found a value of $\mathrm{q}_{\mathrm{e}}$ of approximately 0.125 $\mathrm{mg} \mathrm{g}^{-1}$. This result has demonstrated that Cacen presented greater removal capacity of DS than the inorganic material. 


\section{Conclusion}

Chitosan was modified with acetylacetone and ethylenediamine in the absence of solvent and at reflux, showing this route as a promising way of reaction with other materials, as well as other modifications in the chitosan. The success of the reaction was confirmed by elemental analysis, through the variation of the $\mathrm{C} / \mathrm{N}$ ratio, by FTIR with he presence of the band related to the $\mathrm{C}=\mathrm{N}$ bond to both materials, through the ${ }^{13} \mathrm{C}$ NMR, with the emergence of the shifts related to the imine bonds and by DSC due to the displacement of the peak of exothermic decomposition of amino groups.

The material obtained was applied in the removal of diclofenac sodium, where was observed that the $\mathrm{pH}$ and time greatly influenced the adsorption process. The optimum $\mathrm{pH}$ for the removal of diclofenac sodium in aqueous medium, using Cacen was 4 and the time was 45 minutes, in which the data followed the kinetic model of pseudo second order.

\section{Acknowledgements}

The authors are indebted to CAPES, CNPQ and UFPI.

\section{References}

1. Debrassi A, Largura MCT and Rodrigues CA. Adsorção do corante vermelho congo por derivados da O-Carboximetilquitosana hidrofobicamente modificados. Química Nova. 2011; 34:764-770. http://dx.doi.org/10.1590/ S0100-40422011000500007

2. Silva Filho EC, Monteiro PDR, Sousa KS and Airoldi C. Ethylenesulfide as a useful agent for incorporation on the biopolymer chitosan in a solvent-free reaction for use in lead and cadmium removal. Journal of Thermal Analysis and Calorimetry. 2011; 106:369-373 http://dx.doi.org/10.1007/ s10973-010-1205-y

3. Sousa KS, Silva Filho, EC and Airoldi C. Ethylenesulfide as a useful agent for incorporation into the biopolymer chitosan in a solvent-free reaction for use in cátion removal. Carbohydrate Research. 2009; 344:1716-1723. http://dx.doi.org/10.1016/j. carres.2009.05.028

4. Silva Filho EC, Melo JCP and Airoldi C. Preparation of ethylenediamine-anchored cellulose and determination of thermochemical data for the interaction between cations and basic centers at the solid/liquid interface. Carbohydrate Research. 2006; 341:2842-2850 http://dx.doi.org/10.1016/j. carres.2006.09.004

5. Peng H, Pan B, Wu M, Liu Y, Zhang D and Xing B. Adsorption of ofloxacin and norfloxacin on carbon nanotubes: hydrophobicity- and structure controlled process. Journal of Hazardous Materials. 2012; 233-234:89-96. http://dx.doi. org/10.1016/j.jhazmat.2012.06.058

6. Reif R, Suárez S, Omil F and Lema JM. Fate of pharmaceuticals and cosmetic ingredients during the operation of a MBR treating sewage. Desalination. 2008; 221:511-517. http:// dx.doi.org/10.1016/j.desal.2007.01.111

7. Focazio MJ, Kolpin DW, Barnes KK, Furlong ET, Meyer MT, Zaugg SD et al. A national reconnaissance for pharmaceuticals and other organic wastewater contaminants in the United States - II) Untreated drinking water sources. Science of the Total Environmen. 2008; 402:201-216. http://dx.doi. org/10.1016/j.scitotenv.2008.02.021

8. Silva Filho EC, Lima LCB, Silva FC, Sousa KS, Fonseca MG and Santana SAA. Immobilization of ethylene sulfide in aminated cellulose for removal of the divalent cations. Carbohdyrate Polymers. 2013; 92:1203-1210. http://dx.doi. org/10.1016/j.carbpol.2012.10.031

9. Santana SAA, Vieira AP, Silva Filho EC, Melo JCP and Airoldi C. Immobilization of ethylensulfide on babassu coconut epicarp and mesocarp for divalent cátion sorption. Jornal of Hazardous Materials. 201; 174:714-719.

10. Antunes M, Esteves VI, Guégan R, Crespo JS, Fernandes AN and Giovanela M. Removal of diclofenac sodium from aqueous solution by Isabel grape bagasse. ChemicaL Engineering Journal. 2012; 192:114-121. http://dx.doi.org/10.1016/j. cej.2012.03.062

11. Silva MMF, Oliveira MM, Avelino MC, Fonseca MG, Almeida RKS and Silva Filho EC, Adsorption of na industrial anionic dye by modified-KSF-montmorrilonite: Evaluation of the kinetic, thermodynamic and equilibrium data. Chemical Engineering Journal. 2012; 203:259-268. http://dx.doi. org/10.1016/j.cej.2012.07.009

12. Özacar M and Sengil AI. Application of kinetic models to the sorption of disperse dyes onto alunite. Colloids and Surface A: Phycicochemical and Engineering Aspects. 2004; 242:105-113. http://dx.doi.org/10.1016/j.colsurfa.2004.03.029

13. Silva Filho EC, Melo JCP, Fonseca MG and Airoldi C. Cation removal using cellulose chemically modified by a Schiff base procedure. Journal of Colloid and Interface Science. 2009; 340:8-15. http://dx.doi.org/10.1016/j.jcis.2009.08.012

14. Sakkayawong N, Thiravetyan P and Nakbanpote W. Adsorption mechanism of synthetic reactive dye wastewater by chitosan. Journal of Colloid and Interface Science. 2005; 286:36-42. http://dx.doi.org/10.1016/j.jcis.2005.01.020

15. Barros FCF, Cavalcante RM, Carvalho TV, Dias FS, Queiroz DC and Vasconcelos LCG et al. Produção e Caracterização de esferas de quitosana modificada quimicamente. Revista Iberoamericana de Polímeros. 2006; 7:232-246.

16. Santos JE, Soares JP, Dockal ER, Campana Filho SP and Cavalheiro ETG. Caracterização de quitosanas comerciais de diferentes origens. Polímeros. 2003; 13:242-249. http://dx.doi. org/10.1590/S0104-14282003000400009

17. Machado MO, Lopes ECN, Sousa KS and Airoldi C. The effectiveness of the protected amino group on crosslinked chitosans for copper removal and the thermodynamics of interaction at the solid/liquid interface. Carbohydrate Polymers. 2009; 77:760-766. http://dx.doi.org/10.1016/j. carbpol.2009.02.031

18. Amaral IF, Granja PL and Barbosa MA. Chemical modification of chitosan by phosphorytalation: na XPS, FT-IR and SEM study. Journal of Biomaterials Science Polymer Edition. 2005; 16:1575-1593. http://dx.doi. org/10.1163/156856205774576736

19. Guinesi LS and Cavalheiro ETG. The use of DSC curves to determine the acetylation degree of chitin/chitosan samples. Thermochimica Acta. 2006; 444:128-133. http://dx.doi. org/10.1016/j.tca.2006.03.003

20. Krajisnik D, Dakovic A, Milojevic M, Malenovic A, Kragovic M, Bogdanovic DB et al. Properties of diclofenac sodium sorption onto natural zeolite modified with cetylpyridinium chloride. Colloids and Surfaces B: Biointerfaces. 2011; 83:165172. http://dx.doi.org/10.1016/j.colsurfb.2010.11.024

21. Bui TX and Choi H. Adsortive removal of selected pharmaceuticals by mesoporous silica SBA-15. Journal of Hazardous Materials. 2009; 168:602-608. http://dx.doi. org/10.1016/j.jhazmat.2009.02.072 